\title{
Abnormalities in Membrane Phospholipid Organization in Sickled Erythrocytes
}

\author{
Bertram Lubin and Danny Chiu, Bruce Lyon Memorial Research Laboratory \\ and Department of Hematology/Oncology, Children's Hospital Medical Center, \\ Oakland, California 94609 \\ JACOB BASTACKY, Donner Laboratory, University of California, \\ Berkeley, California \\ Ben Roelofsen and L. L. M. Van Deenen, Department of Biochemistry, \\ State University of Utrecht, The Netherlands
}

\begin{abstract}
A B S T R A C T In contrast to the wealth of information concerning membrane phospholipid asymmetry in normal human erythrocytes, very little is known about membrane phospholipid organization in pathologic erythrocytes. Since the spectrin-actin lattice, which has been suggested to play an important role in stabilizing membrane phospholipid asymmetry, is abnormal in sickled erythrocytes, we determined the effects of sickling on membrane phospholipid organization. We used two enzymatic probes: bee venom phospholipase $\mathrm{A}_{2}$ and Staphylococcus aureus sphingomyelinase $\mathrm{C}$, which do not penetrate the membrane and react only with phospholipids located in the outer leaflet of the bilayer. Our results suggest that the distribution of glycerophospholipids within the membrane of sickled cells is different from that in nonsickled cells. Compared with the normal erythrocyte, the outer membrane leaflet of the deoxygenated, reversibly sickled cells (RSC) and irreversibly sickled cells (ISC) was enriched in phosphatidyl ethanolamine in addition to containing phosphatidyl serine. These changes were compensated for by a decrease in phosphatidyl choline in that layer. The distribution of sphingomyelin over the two halves of the bilayer was unaffected by sickling. In contrast to ISC, where the organization of phospholipids was abnormal under both oxy and deoxy conditions, reoxygenation of RSC almost completely restored the organization of membrane phospholipids to normal. These results indicate that the process of sickling induces an abnormality in the organization of membrane lipids in RSC which becomes permanent in ISC.
\end{abstract}

\section{INTRODUCTION}

The erythrocyte membrane has been a major target of investigation in sickle cell anemia and many abnor-

Received for publication 24 November 1980 and in revised form 9 February 1981. malities in membrane properties have been detected. These abnormalities include increased cation leak $(1,2)$, increased accumulation of calcium (3), increased binding of hemoglobin (4), abnormal protein phosphorylation (5), and increased susceptibility to lipid peroxidation (6). These abnormal properties are accentuated by sickling and are most prominent in irreversibly sickled cells (ISC). ${ }^{1}$ Although related to the polymerization of sickle hemoglobin, the exact mechanism leading to these defects is unknown.

Specific membrane protein abnormalities, such as abnormal glycoprotein patterns, have been reported in reversibly sickled cells (RSC) $(7,8)$. Studies on tritonextracted erythrocyte ghosts obtained from ISC indicate a permanent alteration in the membrane protein cytoskeleton (9). The normal relationship between spectrin and actin is distorted in the ISC and polymerization of these two proteins appears to fix the cell in the sickled configuration. Near-neighbor analysis of membrane proteins using cross-linking agents has also shown a difference in membrane protein organization in ISC compared with RSC or normal erythrocytes (10).

Since evidence is accumulating to suggest that membrane proteins, particularly spectrin, play an important role in stabilizing the organization of membrane phospholipids (11-16), it is not surprising that abnormalities in the organization of certain phospholipid classes have been reported in sickle erythrocytes. In particular, the organization of amino phospholipids within the membrane, as detected by chemical probes, is abnormal $(17,18)$. Dinitrofluorobenzene (DNFB), a probe which penetrates the membrane and reacts with amino groups on both sides of the bilayer, does not bind as

${ }^{1}$ Abbreviations used in this paper: ISC, irreversibly sickled cell; PBS, phosphate-buffered saline; PC, phosphatidyl choline; PE, phosphatidyl ethanolamine; PS, phosphatidyl serine; RBC, erythrocyte; RSC, reversibly sickled cell; SM, sphingomyelin; TNBS, trinitrobenzene sulfonic acid. 
extensively to phosphatidyl ethanalamine (PE) or phosphatidyl serine (PS) in oxygenated sickle erythrocytes as it does in normal erythrocytes (17). Trinitrobenzene sulfonic acid (TNBS), used under incubation conditions in which it did not penetrate the membrane, trinitrophenylated more PE and PS in sickled erythrocytes (RBC) than in normal RBC (18). The findings with these two chemicals probes are consistent with an abnormal organization of aminophospholipids in sickled cells. However, the penetration of small molecules such as TNBS within the RBC membrane can change depending upon experimental conditions (19), and sickling may facilitate penetration of these probes into the bilayer, thereby enhancing the reaction with aminophospholipids located within the inner leaflet. Moreover, because TNBS does not react with phosphatidyl choline (PC) or sphingomyelin (SM), the organization of choline-containing phospholipids in sickled erythrocytes could not be measured using this probe.

Phospholipases have been used extensively to determine membrane phospholipid organization in RBC from normal individuals (20-23). Among these phospholipases are phospholipase $A_{2}$ from bee venom and sphingomyelinase C from Staphylococcus aureus. These phospholipases, provided that they are highly purified, do not penetrate the membrane, do not cause cell lysis, and consequently degrade only those phospholipids located within the outer leaflet of the lipid bilayer. In our present report, we describe the use of these two enzymatic probes to determine the organization of phospholipids within sickled and nonsickled cells. We also use these two probes to determine the effect of unsickling on membrane phospholipid asymmetry within RSC.

\section{METHODS}

Blood collection and sample preparation. Blood samples from patients with sickle cell disease and from normal controls were collected in acid citrate dextrose and filtered through a mixture of microcrystalline cellulose and cellulose to remove white cells (24). A RSC fraction was prepared using a modified procedure of the fixed angle and slow centrifugation method of Lux et al. (9). Filtered sickle RBC were oxygenated and centrifuged at room temperature in a Sorvall centrifuge (SS 34 rotor) for $45 \mathrm{~min}$ at $500 \mathrm{~g}$, followed by a 60 -min centrifugation at $1,000 \mathrm{~g}$. The top $70 \%$ of the sample was collected and used for the RSC experiments. This fraction contained $<1 \%$ ISC. To obtain homogenous subpopulations of normal and sickled erythrocytes, previously filtered RBC were separated according to density into top, middle, and bottom fractions on discontinuous stractan gradients (25). Top and middle fractions of sickle cell blood contained $<2 \%$ ISC, whereas bottom fractions contained $>70 \%$ ISC. The top fractions were rich in reticulocytes (sickle $>25 \%$, normal 5-8\%), whereas the bottom fractions were devoid of reticulocytes.

Treatment of RBC with phospholipase $A_{2}$ and sphingomyelinase $C$ under oxygenated, deoxygenated, and reoxy- genated conditions. A $0.25-\mathrm{ml}$ aliquot of packed RBC was resuspended in $5.0 \mathrm{ml}$ of $10 \mathrm{mM}$ glycylglycine buffer containing $100 \mathrm{mM} \mathrm{KCl}, 50 \mathrm{mM} \mathrm{NaCl}, 0.25 \mathrm{mM} \mathrm{Mg}^{+2}, 0.25 \mathrm{mM}$ $\mathrm{Ca}^{+2}$, and $44 \mathrm{mM}$ sucrose, $\mathrm{pH} 7.4$; and preincubated under either humidified $95 \% \mathrm{~N}_{2}: 5 \% \mathrm{CO}_{2}$ or room air at $37^{\circ} \mathrm{C}$ for $1 \mathrm{~h}$. $15 \mathrm{IU}$ of phospholipase $A_{2}$ from bee venom (Sigma Chemical Co., St. Louis, Mo.) or $10 \mathrm{IU}$ of sphingomyelinase from $S$. aureus, purified by the method of $Z_{\text {waal }}$ et al. (21), was then added to these samples, and the incubations were continued for appropriate time intervals while $\mathrm{pH}$ and $\mathrm{RBC}$ ATP levels (26) were monitored. The purity of both phospholipase $A_{2}$ from bee venom and sphingomyelinase from S. aureus was tested by sodium dodecyl sulfate (SDS) polyacrylamide gel electrophoresis. A single band was detected with both enzyme preparations.

The degradation of phospholipid by phospholipase $A_{2}$ or sphingomyelinase was terminated by washing the RBC three times with phosphate-buffered saline (PBS) containing $5 \mathrm{mM}$ EDTA. The extent of hemolysis was determined at the end of each incubation prior to the EDTA wash by comparing the hemoglobin content in the supernate of each sample to that of a $100 \%$ hemolyzed control. In the reoxygenation experiments, RBC were first induced to sickle by incubating them under $95 \% \mathrm{~N}_{2}: 5 \% \mathrm{CO}_{2}$ for $1 \mathrm{~h}$. After a portion of the deoxygenated cell suspension was removed to measure membrane phospholipid organization, the remaining sickled cells were reincubated under $95 \% 0_{2}: 5 \% \mathrm{CO}_{2}$ for an additional hour until they returned to a biconcave shape. These reoxygenated cells were then incubated with phospholipase $A_{2}$ as previously described to determine membrane phospholipid organization.

Determination of phospholipid degradation by phospholipase $A_{2}$ and sphingomyelinase $C$. Phospholipase-treated and control RBC samples were washed with PBS and were subjected to lipid extraction by the method of Rose and Oklander (27). Lipid extracts from each sample were evaporated to dryness under nitrogen and redissolved in a small volume $(100-200 \mu \mathrm{l})$ of $2: 1$ chloroform:methanol mixture. Individual phospholipids were separated by the two-dimensional thin-layer chromatographic technique described by Roelofsen and Zwaal (28). The individual lipid components were examined by staining with iodine vapor. All spots were scraped from the plate and transferred to test tubes; and the quantity of phospholipid was determined by measuring the amount of phosphorus in each spot, using the method of Bottcher et al. (29).

The percentage of phospholipid hydrolyzed after treatment of RBC with phospholipase $A_{2}$ was determined by measuring the ratio of remaining diacylglycerophospholipid to the corresponding lyso derivative. For the determination of SM degradation by sphingomyelinase, the absolute and relative quantity of SM recovered from the sample was compared with the absolute and relative quantity of SM recovered from the nontreated control sample.

Scanning electron microscopy of phospholipase $A_{2}$-treated $R B C$. RBC were removed from each incubation mixture after the 2-h exposure to phospholipase $A_{2}$ and were fixed in PBS containing $2 \%$ glutaraldehyde in which oxygenated and deoxygenated conditions were maintained. Fixed cells were allowed to attach to glass coverslips covered with polylysine to enhance adherence. Coverslips with cells attached to them were dehydrated in a graded acetone series, critical point-dried from liquid $\mathrm{CO}_{2}$, and mounted on stubs. A thin film $(\sim 20 \mathrm{~nm})$ of gold or platinum was deposited on the surface of the cells in a refrigerated triode sputter coater (to enhance conductivity and increase secondary electron coefficients). Samples were examined in an AMR-1000 A scanning electron microscope at $20 \mathrm{kV}$ at various tilted angles and various magnifications. 


\section{RESULTS}

Although $\sim 20 \%$ of the total phospholipid content of the membrane was hydrolysed by phospholipase $\mathrm{A}_{2},<2 \%$ hemolysis was noted in phospholipase $\mathbf{A}_{2}$-treated cells. A similar mild degree of hemolysis was observed in
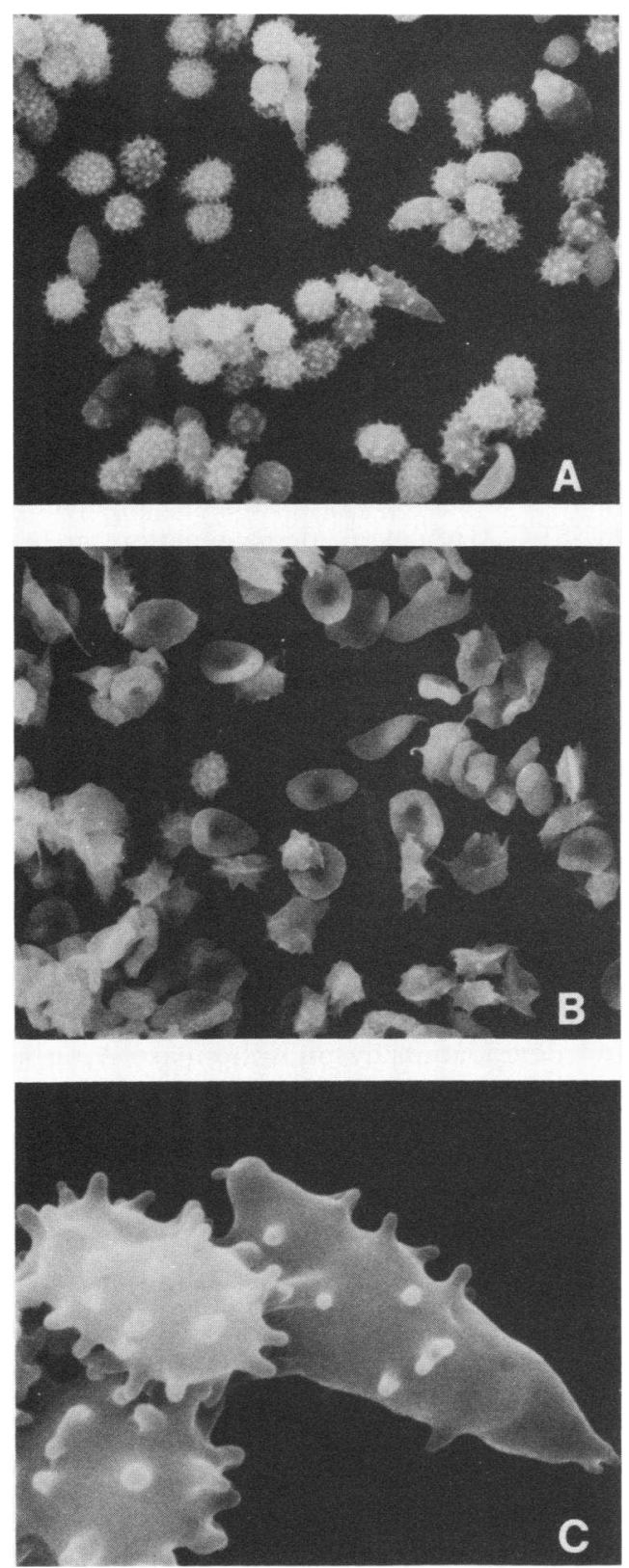

FIGURE 1 Scanning electron micrographs of sickle RBC treated with bee venom phospholipase $A_{2}$. (A) RSC and ISC under oxygenated conditions exhibiting echinocytic transformation (B) RSC and ISC under deoxygenated conditions demonstrating predominantly sickled forms. (C) Detail of micrograph A. The morphology of reoxygenated phospholipase $A_{2}$-treated RSC was identical to that of Fig. 1A. sphingomyelinase-treated cells. The extent of hemolysis was identical in sickle and normal RBC and was not increased by hypoxia. The degraded materials, lysophospholipids in the case of phospholipase $\mathrm{A}_{2}$ and ceramide in the case of sphingomyelinase $\mathrm{C}$, remained in the membrane and were completely recovered in the lipid extract.

Fig. 1 shows the morphology of phospholipase $\mathbf{A}_{2^{-}}$ treated sickle RBC under oxygenated (Fig. 1A) and deoxygenated (Fig. 1B) conditions. The echinocytic transformation in oxygenated sickle erythrocytes was similar to that reported in normal RBC (30). In contrast, deoxygenated sickle RBC failed to undergo echinocytic transformation (Fig. 1B). Upon reoxygenation, however, the phospholipase $\mathrm{A}_{2}$-treated sickle RBC promptly became echinocytes (similar morphology to those in Fig. 1A). It is interesting to note that echinocytic transformation in ISC is different from that in RSC. In the ISC, although echinocytes were formed, the projections were fewer than in RSC and were unequally distributed on the surface of the membrane. These differences are more apparent under higher magnification (Fig. 1C).

Table I shows the results of the phospholipase experiments in oxygenated and deoxygenated RSC. After a 2-h incubation, there are major differences in the pattern of glycerophospholipid hydrolysis in deoxygenated RSC (PC, 48 $\pm 4.1 \%$ PE, $24 \pm 3.5 \%$, PS, $10 \pm 2.1 \%$ ) as compared with the oxygenated RSC (PC, $58 \pm 3.4 \%$, PE, $11 \pm 1.9 \%$, PS, $0 \%$ ). Hypoxia had no effect on the hydrolysis of phospholipids in normal RBC or

\section{TABLE I}

Phospholipid Degradation in Oxygenated RSC, Deoxygenated $R S C$, and Normal RBC by Phospholipase $A_{2}$ Obtained from Bee Venom

\begin{tabular}{|c|c|c|c|c|c|}
\hline RBC samples & $n$ & PC & PE & PS & SM \\
\hline & \multicolumn{5}{|c|}{$\%$} \\
\hline \multicolumn{6}{|l|}{ Oxygenated } \\
\hline RSC & 8 & $58 \pm 3.4$ & $11 \pm 1.9$ & - & $82 \pm 4.0$ \\
\hline $\begin{array}{l}\text { Deoxy- } \\
\text { genated }\end{array}$ & & & & & \\
\hline RSC & 8 & $48 \pm 4.1$ & $24 \pm 3.5$ & $10 \pm 2.1$ & $84 \pm 5.6$ \\
\hline $\begin{array}{c}\text { Oxygenated } \\
\text { normal }\end{array}$ & & & & & \\
\hline RBC & 10 & $60 \pm 2.9$ & $11 \pm 2.0$ & - & $82 \pm 3.8$ \\
\hline $\begin{array}{l}\text { Deoxy- } \\
\text { genated } \\
\text { normal }\end{array}$ & & & & & \\
\hline RBC & 10 & $61 \pm 3.0$ & $10 \pm 1.6$ & - & $83 \pm 4.1$ \\
\hline
\end{tabular}

Oxygenated samples were first incubated under room air for $1 \mathrm{~h}$, and deoxygenated samples were first incubated under $95 \% \mathrm{~N}_{2} / 5 \% \mathrm{CO}_{2}$ for $1 \mathrm{~h}$ before treatment with phospholipase $\mathrm{A}_{2}$ for $2 \mathrm{~h}$. All values are mean \pm 1 SD. $n$, number of experiments. 


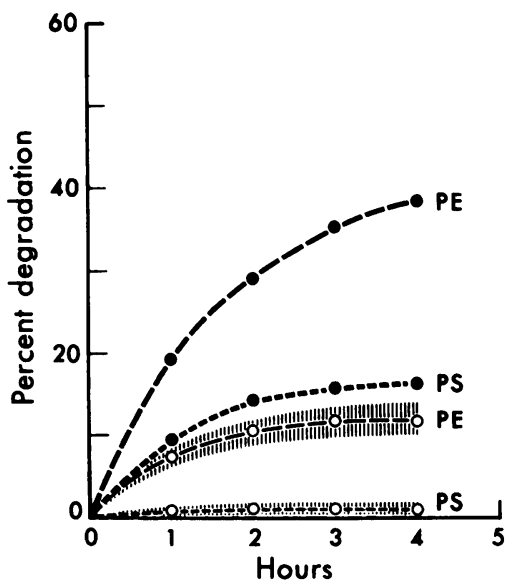

FIGURE 2 Influence of sickling on the degradation of aminophospholipid in RSC by phospholipase $A_{2}$ from bee venom. Percent degradation of PE and PS in RSC by phospholipase $A_{2}$ under either oxygenated $(O)$ or deoxygenated $(O)$ condition was plotted against phospholipase $\mathbf{A}_{2}$ incubation time. \|II, Normal range.

on the degradation of SM in either RSC, ISC, or normal RBC. The total amount of phospholipid hydrolyzed by phospholipase $A_{2}$ in hypoxic sickled RSC was $23 \pm 2.5 \%$, compared with $21 \pm 1.6 \%$ in oxygenated RSC. Since the quantity of each phospholipid class remained stable throughout these incubations, the increased degradation of $\mathrm{PE}$ and $\mathrm{PS}$ together with the decreased degradation of PC suggests that, during sickling, $\mathrm{PC}$ is translocated from the outer leaflet to the inner leaflet in exchange for PE and PS.

Since our previous studies with TNBS indicated that the organization of aminophospholipids was abnormal in sickled cells, we determined the effects of sickling on the kinetics of aminophospholipid translocation using phospholipase $A_{2}$. Fig. 2 shows the effects of sickling induced by deoxygenation on the rate of aminophos- pholipid degradation. The pattern of hydrolysis in oxygenated RSC during a 4-h incubation was identical to normal RBC, with little or no PS degradation and $12 \% \mathrm{PE}$ degradation. The degradation of $\mathrm{PE}$ reached a maximum by $3 \mathrm{~h}$. In contrast, when RSC were completely sickled, a marked increase in degradation of both PE (40\%) and PS (15\%) was observed. Furthermore, this increase did not plateau even at $4 \mathrm{~h}$.

To determine the organization of membrane phospholipids in reticulocytes and ISC, RBC from healthy, normal individuals and sickle cell patients were separated into top, middle, and bottom fractions on a discontinuous stactan gradient, and these subpopulations were treated with phospholipase $A_{2}$ under either oxygenated or deoxygenated conditions. The results of these experiments are shown in Table II. The amount of aminophospholipids degraded in both top and middle fractions of sickle RBC under oxygenated conditions was almost identical to that in all fractions of normal RBC. Deoxygenation had no influence on degradation of aminophospholipids in all fractions of normal RBC. However, deoxygenation greatly enhanced the degradation of aminophospholipids in both top and middle fractions of sickle erythrocytes (PE from 14 to $24 \%$, PS from $<1$ to $9 \%$ ) after $2 \mathrm{~h}$ of degradation. In contrast to the degradation of aminophospholipids in top and middle fractions of sickle RBC under oxygenated and deoxygenated conditions, the degradation of aminophospholipids in the ISCrich bottom fractions of sickle RBC was abnormal (PS, $9 \%, \mathrm{PE}, 26 \%$ ) even under oxygenated conditions. Furthermore, deoxygenation had very little influence on the degradation of aminophospholipids in the ISCrich bottom fractions.

To determine whether the abnormal pattern of phospholipid degradation by phospholipase $A_{2}$ in sickled RSC could be reversed back to normal when the cells were returned to the biconcave disc shape, RSC were

TABLE II

Degradation of Aminophospholipids by Phospholipase $A_{2}$ Obtained from Bee Venom in Subpopulations of Erythrocytes Incubated under Nitrogen or Air

\begin{tabular}{lccccccr}
\hline & \multicolumn{3}{c}{ PE } & & \multicolumn{2}{c}{ PS } \\
\cline { 2 - 3 } \cline { 5 - 6 } RBC sample & Top & Middle & Bottom & & Top & Middle & Bottom \\
\hline Sickle cell (4) & & $\%$ & & & $\%$ & \\
$\quad$ Air & & & & & & $9 \pm 2.4$ \\
$\quad$ Nitrogen & $14 \pm 2.2$ & $14 \pm 1.7$ & $26 \pm 3.0$ & & - & \\
$\quad$ Normal cell (3) & $24 \pm 3.3$ & $24 \pm 3.1$ & $28 \pm 3.9$ & & $8 \pm 2.5$ & $9 \pm 2.8$ & $10 \pm 3.2$ \\
$\quad$ Air & $14 \pm 1.9$ & $14 \pm 1.6$ & $14 \pm 2.3$ & & - & - & - \\
$\quad$ Nitrogen & $12 \pm 2.1$ & $14 \pm 1.7$ & $13 \pm 2.0$ & & - & - & - \\
\hline
\end{tabular}

Both top and middle fractions of sickle erythrocytes contain $<2 \%$ ISC. Bottom fraction of sickle erythrocytes contains $>70 \%$ ISC. Values are mean \pm 1 SD. Numbers in parentheses indicate the number of experiments. 
sickled under nitrogen for $1 \mathrm{~h}$, a sample was removed to determine phospholipid organization, and then reoxygenated prior to incubation with phospholipase $A_{2}$. The results of these experiments are shown in Table III. The abnormalities in membrane phospholipid organization in RSC that had been induced by sickling were almost completely corrected when the cells were converted back to biconcave disks. However, a slight increase in degradation of PE (from 12 to $17 \%$ ) and decrease in degradation of PC (from 59 to $54 \%$ ) by phospholipase $\mathrm{A}_{2}$ persisted in these reoxygenated cells.

\section{DISCUSSION}

These studies suggest that sickling causes an alteration in the organization of glycerophospholipids within the lipid bilayer. The most notable changes that occurred during sickling were seen in the aminophospholipids, with PE and PS translocated from the inner leaflet of the lipid bilayer to the outer leaflet. An additional observation during sickling was that part of the PC appeared to transfer from the outer to the inner leaflet, in exchange for PE and PS. In contrast, the distribution of SM within the bilayer was not affected by sickling. Taken together, these results suggest that sickling induces a more ranclomized glycerophospholipid distribution between the two membrane lipid layers. To a certain extent, this process is reversible; however, after reoxygenation, PE and PC do not completely return to their normal location in the bilayer. Furthermore, during the process of ISC formation, these alterations in the organization of glycerophospholipids become permanent.

For normal cells, a complete picture of the transbilayer distribution of the glycerophospholipids is only obtained when the cells are first treated with phospholipase $A_{2}$ and then with sphingomyelinase C. Unfortunately, such a treatment cannot be applied to the sickled cells, as we have found that the combined action of these phospholipases treatment results in ex-

TABLE III

Effect of Reoxygenation on Phospholipid Degradation by Phospholipase $\mathrm{A}_{2}$ in RSC

\begin{tabular}{cccc}
\hline RBC samples & PC & PE & PS \\
\hline Oxygenated RSC $(n=4)$ & $59 \pm 2.8$ & $12 \pm 1.5$ & - \\
Deoxygenated RSC $(n=4)$ & $50 \pm 3.6$ & $25 \pm 5.3$ & $13 \pm 2.4$ \\
Reoxygenated RSC $(n=4)$ & $54 \pm 3.1$ & $17 \pm 4.0$ & -
\end{tabular}

Oxygenated RSC, were preincubated under room air for $1 \mathrm{~h}$, and deoxygenated RSC were preincubated under $95 \%$ $\mathrm{N}_{2} / 5 \% \mathrm{CO}_{2}$ for $1 \mathrm{~h}$. All samples were treated with phospholipase $A_{2}$ for 2 l. $n$, number of experiments. The mean and $1 \mathrm{SD}$ are shown. tensive hemolysis (unpublished data). Nevertheless, our results with phospholipase $\mathrm{A}_{2}$ alone clearly indicate that there are alterations in the distribution of PE, PS, and PC with in the bilayer in the sickled state.

It must be pointed out that many factors can affect the extent of phospholipid hydrolysis by phospholipase $A_{2}$. It has been shown that normal RBC, when aged in vitro, show a marked increase in susceptibility of $\mathrm{PE}$ to phospholipase degradation under nonlytic conditions (31). Other factors such as $\mathrm{pH}$ or ATP levels can also alter the extent of PC, PE, or PS hydrolysis of normal RBC by phospholipase $A_{2}(22)$. Since both pI and ATP levels were found to be stable throughout the incubation period, this excludes the possibility that the observed difference in membrane phospholipid degradation by phospholipase $A_{2}$ between sickled and nonsickled RBC is related to $\mathrm{pH}$ and ATP. Furthermore, our data on membrane phospholipid organization in subpopulations of cells from both normal individuals and sickle cell patients (Table II) clearly indicates that the difference in membrane phospholipid degradation by phospholipase $\mathrm{A}_{2}$ between sickled and nonsickled $\mathrm{RBC}$ was not a nonspecific phenomenon related to the age of the $\mathrm{RBC}$, but rather a specific phenomenon related to sickling.

Sickling could affect the penetration of phospholipase $A_{2}$ into the membrane in such a way that an abnormal quantity of aminophospholipids was degraded. Alternatively, the penetration of phospholipase $A_{2}$ into the RBC membrane could be affected by a reversible shielding-unshielding of phospholipid on the periphery of the cell in oxygenated or deoxygenated states. However, our results are also consistent with a translocation of phospholipids between the two halves of the bilayer. In contrast to sickled cells, convincing evidence has recently been presented that, at least for the PC fraction, translocation does not exist in normal human RBC (32). However, since the time curve for the hydrolysis of PE and PS in sickled cells does not end up on a clear platean (Fig. 2), as is the case with nonsickled cells, the possibility of a translocation mechanism cannot be excluded.

The factors that control the rearrangement of phospholipids within the lipid bilayer during sickling are unknown. Evidence is gradually acumulating to suggest that spectrin may play an important role in stabilizing membrane phospholipid organization in human RBC (11-16). Spectrin has been demonstrated to interact with phospholipids in artificial membrane systems (12-14). Oxidation of spectrin by sulfhydryl oxidizing agents causes alteration in membrane phospholipid asymmetry in human RBC with increased amounts of PF and PS exposed to the other leaflet of the lipid bilayer (14). Oxidation of spectrin by diamide also enhances transbilayer reorientation of phospholipids (15). Prevention of formation of 
myelin figures and membrane lipid loss by binding spectrin to spectrin-deficient mouse RBC membranes is consistent with a membrane lipid stabilizing role for spectrin (16). From these results, together with the fact that spectrin is irreversibly deformed in ISC (9), we speculate that an alteration in spectrin may underlie the observed abnormalities in membrane phospholipid organization in sickled RBC and in ISC.

In addition to spectrin, calcium may be involved in the translocation of phospholipids. Since membranebound calcium increases during sickling (3), calcium may interact with PE or PS molecules located within the inner leaflet of the bilayer. Formation of such a complex in sickle erythrocytes would make translocation of phospholipids thermodynamically more favorable than in normal RBC. However, additional data are needed to confirm this hypothesis, and experiments are being formulated to define the exact mechanism of this transbilayer movement of phospholipids.

After treatment with phospholipase $A_{2}$, normal erythrocytes rapidly undergo echinocytic transformation. This phenomenon is probably due to the presence of lysophospholipids primarily in the outer leaflet of the membrane. Our observation that echinocyte formation does not occur in deoxygenated sickle cells suggests that polymerized sickle hemoglobin may interact with the spectrin-actin complex and thus exert a restraining effect on the membrane. This hypothesis is supported by the rapid appearance of echinocytes when these deoxygenated, phospholipase-treated cells are reoxygenated. In the oxygenated ISC, echinocytic transformation is also abnormal, further suggesting a relationship between cytoskeletal structure and echinocytic transformation.

Although the pathophysiologic significance of abnormal membrane phospholipid asymmetry in sickle erythrocytes is not clear, possible implications have emerged from several recent observations. Zwall et al. (33) have provided evidence to suggest that the asymmetric distribution of membrane phospholipids in blood cells may serve a biological purpose by contributing to the delicate balance between regulating hemostasis and avoiding thrombosis. We recently presented evidence to indicate that a disruption of the normal membrane phospholipid asymmetry in sickle RBC by the sickling process enhances blood coagulation in vitro (34). These results suggest that abnormal membrane phospholipid organization in sickled RBC may contribute to the pathophysiology of vaso-occlusive crisis.

It is also possible that abnormal externalization of PS in sickled RBC may enhance the adherence of these cells to vascular endothelium. Recent studies by Hoover et al. (35) and Hebbel et al. (36) demonstrate that the adherence of sickle RBC to endothelial cells is greater than the adherence of normal erythrocytes, and this abnormality has been suggested to be the initiating factor in the development of microvascular occlusions in sickle cell anemia (35-37). Negatively charged residues, primarily sialic acid, on the membrane surface have been suggested as factors likely to affect adherence of RBC to vascular endothelium (36). However, the role of aminophospholipids in the interaction has not been investigated. Together with the observation of Wilschut and Papahajopoulos (38) that negatively charged PS and calcium ions are essential for cell-to-cell contact leading to cell fusion, it is possible that abnormal externalization of PS on sickle RBC membranes has a role in enhancement of in vitro adherence of sickle RBC to endothelial cells.

If abnormal membrane phospholipid organization indeed has pathophysiologic significance, membrane phospholipid organization in pathologic RBC other than sickle RBC should be determined. Since spectrin appears to be an important factor in stabilizing membrane phospholipid organization, membrane phospholipid asymmetry in RBC from patients suspected to have a defect in spectrin such as hereditary spherocytosis, elliptocytosis, and pyropoikilocytosis (39) should also be examined.

\section{ACKNOWLEDGMENTS}

The authors would like to thank Dr. Y. Beuzard and Dr. J. Rosa of Henri Mondor Hospital, Institut National de la Santé et de la Recherche Medicale, U91, Creteil, France for their assistance in carrying out several of the experiments described in this article. The authors are also in debt to Dr. Shohet for his critical review of this manuscript.

This study was supported in part by U. S. Public Health Service HL-20985 and in part by a National Research Service Award (F32-HL05694) from the National Heart, Lung and Blood Institute.

\section{REFERENCES}

1. Tosteson, D. C., E. Carlson, and E. T. Dunham. 1955. The effects of sickling on ion transport. I. The effect of sickling on potassium transport. J. Gen. Physiol. 39: 31-35.

2. Glader, B. E., A. Muller, and D. G. Nathan. 1974. Comparison of membrane permeability abnormalities in reversibly and irreversibly sickled erythrocytes. In Proceedings of the First National Symposium on Sickle Cell Disease, J. I. Hercules, A. N. Schnechter, W. A. Eaton, and R. E. Jackson, editors. Department of Health, Education, and Welfare publication. 75-723, 55-56.

3. Eaton, J. W., T. D. Skelton, H. S. Swofford, C. E. Kolpin, and H. S. Jacob, 1973. Elevated erythrocyte calcium in sickle cell disease. Nature (Lond.). 246: 105-106.

4. Asakura, T., K. Minakaza, K. Adachi, M. O. Russel, and E. Schwartz. 1977. Denatured hemoglobin in sickle erythrocytes. J. Clin. Invest. 59: 633-640.

5. Hosey, M. M., and M. Tao. 1976. Altered erythrocyte membrane phosphorylation in sickle cell disease. Nature (Lond.). 263: 424-425.

6. Lubin, B., and D. Chiu. 1980. Abnormal susceptibility of sickle erythrocytes to lipid peroxidation. In Red Blood 
Cell and Lens Metabolism. S. Srivastava, editor. Elsevier/ North Holland, New York. 159-162.

7. Riggs, M. C., and V. M. Ingram. 1977. Differences in erythrocyte membrane proteins and glycoproteins in sickle cell disease. Biochem. Biophys. Res. Commun. 74: 191- 198 .

8. Luer, C. A., and K. P. Wong. 1978. Altered erythrocyte membrane proteins in sickle cell patients associated with the severity of the disease. Biochem. Med. 19: 95-107.

9. Lux, S. E., K. M. John, and J. Karnovsky. 1976. Irreversible deformation of the spectrin-actin lattice in irreversible sickled cells. J. Clin. Invest. 58: 955-962.

10. Rubin, R. W., C. Milikowski, and G. E. Wise. 1980. Organizational differences in the membrane proteins of normal and irreversibly sickled erythrocytes. Biochim. Biophys. Acta. 595: 1-8.

11. Sweet, C., and J. E. Zull. 1970. Interaction of the erythrocyte-membrane protein, spectrin, with model membrane system. Biochem. Biophys. Res. Commun. 41: 135-140.

12. Juliano, R. L., H. K. Kimelberg, and D. Papahadjopoulos. 1971. Synergistic effects of a membrane protein (spectrin) and $\mathrm{Ca}^{+2}$ and $\mathrm{Na}^{+}$permeability of phospholipid vesicles. Biochim. Biophys. Acta. 241: 894-901.

13. Mombers, C., P. W. M. van Dijck, L. L. M. van Deenen, J. DeGier, and A. J. Verkleig. 1977. Interaction of spectrin-actin and synthetic phospholipids. Biochim. Biophys. Acta. 470: 152-159.

14. Haest, C. W. M., G. Plasa, D. Kamp, and B. Deuticke. 1978. Spectrin as a stabilizer of the phospholipid asymmetry in the human erythrocyte membrane. Biochim. Biophys. Acta. 509: 21-32.

15. Mohandas, N., J. Wyatt, D. Shelton, and S. Shohet. 1980. Cross-linking of red cell cytoskeletal proteins increases transmembrane lipid movement. Fed. Proc. 39: 1918. (Abstr.)

16. Shohet, S. B. 1979. Reconstitution of spectrin-deficient, spherocytic mouse erythrocyte membranes. J. Clin. Invest. 64: 483-494.

17. Gordesky, S. E., G. V. Marinetti, and B. G. Segel. 1972. Differences in the reactivity of phospholipids with FDNB in normal RBC, sickle cells and RBC ghosts. Biochem. Biophys. Res. Commun. 47: 1004-1009.

18. Chiu, D., B. Lubin, and S. Shohet. 1979. Erythrocyte membrane lipid reorganization during the sickling process. Br. J. Haematol. 41: 223-234.

19. Gordesky, S. E., G. V. Marinetti, and R. Love. 1975. The reaction of chemical probes with the erythrocyte membrane. J. Membr. Biol. 20: 111-132.

20. Colley, C. M., R. F. Zwaal, B. Roelofsen, and L. L. M. Van Deenen. 1973. Lytic and non-lytic degradation of phospholipids in mammalian erythrocytes by pure phospholipases. Biochim. Biophys. Acta. 307: 74-82.

21. Zwaal, R. F. A., B. Roelofsen, P. Comfurius, and L. L. M. Van Deenen. 1975. Organization of phospholipids in human red cell membranes as detected by the action of various purified phospholipases. Biochim. Biophys. Acta. 406: 83-86.

22. Martin, J. K., M. G. Luthra, M. A. Wells, R. P. Watts, and D. J. Hanahan. 1975. Phospholipase $A_{2}$ as a probe of phospholipid distribution in erythrocyte membrane. Factors influencing the apparent specificity of the reaction. Biochemistry. 14: 5400-5408.
23. Roelofsen, B., M. S. Trip, H. M. Verheij, and J. L. Zevenbergen. 1980. The action of cobra venom phospholipase $\mathrm{A}_{2}$ isoenzymes toward intact human erythrocytes. Biochim. Biophys. Acta. 600: 1012-1017.

24. Beutler, E., C. West, and K. G. Blume. 1976. The removal of leukocytes and platelets from whole blood. J. Lab. Clin. Med. 88: 328-333.

25. Clark, M. R., R. C. Unger, and S. B. Shohet. 1978. Monovalent cation composition and ATP and lipid content of irreversibly sickled cells. Blood. 51: 1169-1178.

26. Beutler, E. 1975. Red cell metabolism: a manual of biochemical methods. Grune \& Stratton, New York. 2nd edition. 104-105.

27. Rose, H. G., and M. Oklander. 1965. Improved procedure for the extraction of lipids from human erythrocytes. J. Lipid Res. 6: 428-431.

28. Roelofsen, B., and R. F. A. Zwaal. 1976. The use of phospholipases in the determination of asymmetric phospholipid distribution in membrane. Methods Membr. Biol. 7: 147-177.

29. Bottcher, C. J. F., C. M. van Gent, and C. Pries. 1961. $A$ rapid and sensitive sub-micro-phosphorous determination. Anal. Chim. Acta. 24: 203-208.

30. Fuju, T., and A. Tamura. 1979. Asymmetric manipulation of the membrane lipid bilayer of intact human erythrocytes with phospholipase $\mathrm{A}, \mathrm{C}$, or $\mathrm{D}$ induces a change in cell shape. J. Biochem. (Tokyo). 86: 1345.

31. Shukla, S. D., R. Coleman, J. B. Finean, and R. H. Michell. 1978. The use of phospholipase $C$ to detect structural changes in the membranes of human erythrocytes aged by storage. Biochim. Biophys. Acta. 512: 341-349.

32. Van Meer, G., B. J. H. M. Poorthuis, K. W. A. Wirtz, J. A. F. Op Den Kamp, and L. L. M. Van Deenen. 1980. Transbilayer distribution and mobility of phosphatidylcholine in intact erythrocyte membranes. Eur. J. Biochem. 103: 283-288.

33. Zwaal, R. F., P. Comfurius, and L. L. M. Van Deenen. 1977. Membrane asymmetry and blood coagulation. $\mathrm{Na}$ ture (Lond.). 268: 358-360.

34. Chiu, D., S. Fujimura, and B. Lubin, 1979. Sickled erythrocytes accelerate clotting: an effect of abnormal membrane lipid asymmetry. Blood. 54 (Suppl. 1): 25a. (Abstr.)

35. Hoover, R., R. Rubin, G. Wise, and R. Warren. 1979. Adhesion of normal and sickle erythrocytes to endothelial monolayer cultures. Blood. 54: 872-876.

36. Hebbel, R. P., O. Yamada, C. F. Moldow, H. S. Jacob, J. G. White, and J. W. Eaton. 1980. Abnormal adherence of sickle erythrocytes to cultured vascular endothelium. J. Clin. Invest. 65: 154-160.

37. Hebbel, R. P., M. A. B. Boogaerts, J. W. Eaton, and M. H. Steinberg. 1980. Erythrocyte adherence to endothelium in sickle-cell anemia. A possible determinant of disease severity. N. Engl. J. Med. 302: 992-995.

38. Wilschut, J., and D. Papahadjapoulos. 1979. $\mathrm{Ca}^{+2}$-induced fusion of phospholipid vesicle monitored by mixing of aqueous contents. Nature (Lond.). 281: 690-692.

39. Lux, S. E., and L. C. Wolf. 1980. Inherited disorders of the red cell membrane skeleton. Pediatr. Clin. N. Am. 27: 463-486. 